Technical Section

$===x=$

(Received December 20, 1978)

\title{
DEFORMATION OF POLY(VINYL CHLORIDE), POLYPROPYLENE AND NYLON-6 FIBERS BY RAPID HEATING
}

\author{
By Nobuyuki Tanaka \\ (Faculty of Technology, Gunma University, Kiryu, Gunma-ken, Japan)
}

\begin{abstract}
The thermal deformation phenomena of PVC, PP and nylon- 6 fibers heated rapidly by immersing in silicone oil of a given temperature or by irradiating with infrared ray were reported. The shrinkage rates of PP and PVC fibers were 98 and $105 \mathrm{~mm} / \mathrm{sec}$, respectively, independent of the sample initial length. The rate of nylon- 6 fiber was dependent on the initial length. A damped oscillation of the sample length was found for PVC fiber upon the heating. These results suggest that necking type shrinkage takes place for PP and PVC fibers, but not for nylon-6 fibers. The oscillation of PVC fiber length may be related to the damped inertial elasticity.
\end{abstract}

\section{Introduction}

Rapid heating of polymers induces thermal deformation. The relation between the deformation and the structural change, however, has scarcely been investigated. Clarification of such relation is also important from the viewpoint of the dimensional stability of polymer products. Farrow and Simmens observed the melting behavior of nylon-6 fibers upon rapid heating in dry and in water-saturated atmospheres and found a well-defined core effect and the outbreak of internal cavitation accompanying delustering of the filament. ${ }^{1}$

In this paper, thermal deformation was studied for poly(vinyl chloride) (PVC), polypropylene (PP) and nylon- 6 fibers heated rapidly by immersing in silicone oil maintained at certain temperatures ${ }^{2}$ or by irradiating with infrared ray. The mechanism of thermal shrinkage of these fibers were discussed.

\section{Experimental}

\section{Samples}

As the samples of highly oriented fibers, the commercial monofilaments of PP (375 D) and nylon-6 (320 D), and the multifilament of PVC $(66.3 \mathrm{~d} \times 10$ fils.) were used. No heat treatment of these fibers was performed to avoid any alteration in the structures of the original fibers. The density $\rho$, the crystalline orientation factor $f_{c}$, the amorphous orientation factor $f_{\mathrm{a}}$, the birefringence $\Delta n$, the degree of crystallinity $\alpha$, and the degree of polymerization $x$ of each fiber are listed in Table 1 . $f_{c}$ was evaluated from the half width of the maximum $\mathrm{X}$-ray reflection on the azimuthal scanning of the (1 110$)$ plane for PP fibers and the $\left(\begin{array}{lll}1 & 0 & 0\end{array}\right)$ plane for nylon-6 fibers. $f_{\mathrm{a}}$ was calculated using the relation ${ }^{2}$

$$
f_{\mathrm{a}}=\frac{3}{2}\left(\frac{L_{\mathrm{a}}}{L_{\mathrm{c}}}\right)^{2}-\frac{1}{2}
$$

Table 1. $a, f_{\mathrm{c}}, f_{\mathrm{a}}, \Delta n, \alpha$ and $x$ for PP, nylon- 6 and PVC fibers

\begin{tabular}{|c|c|c|c|c|c|c|}
\hline fibers & $\rho \mathrm{g} / \mathrm{cm}^{3}$ & $f_{\mathrm{c}}$ & $f_{\mathrm{a}}$ & $\Delta n$ & $\alpha \%$ & $x$ \\
\hline PP & $0.8845\left(23^{\circ} \mathrm{C}\right)$ & 0.90 & 0.759 & 0.0339 & 38.1 & 4280 \\
\hline nylon- 6 & $1.141\left(25^{\circ} \mathrm{C}\right)$ & 0.94 & 0.764 & - & 30.0 & 90.4 \\
\hline PVC & $1.378\left(25^{\circ} \mathrm{C}\right)$ & - & - & 0.01 & - & - \\
\hline
\end{tabular}


where $L_{\mathrm{c}}$ is the length of a sample in totally crystalline state and $L_{\mathrm{a}}$ the length in totally amorphous state. The degree of crystallinity $\alpha$ was evaluated using the relation

$$
\alpha=\left(\frac{\rho-\rho_{\mathrm{a}}}{\rho_{\mathrm{c}}-\rho_{\mathrm{a}}}\right)\left(\frac{\rho_{\mathrm{c}}}{\rho}\right)
$$

where $\rho_{\mathrm{c}}$ is the density of the crystalline region and $\rho_{\mathrm{a}}$ the density of the amorphous region (PP: $\rho_{\mathrm{c}}=0.935 \mathrm{~g} / \mathrm{cm}^{3}, \rho_{\mathrm{a}}=0.856 \mathrm{~g} / \mathrm{cm}^{3} ;$ nylon- $6: \rho_{\mathrm{c}}=$ $\left.1.212 \mathrm{~g} / \mathrm{cm}^{3}, o_{\mathrm{a}}=1.113 \mathrm{~g} / \mathrm{cm}^{3}\right)$.

\section{Rapid Heating Methods and Thermal Deformation Measurements}

Rapid heating was performed by means of two methods, one by use of the silicone oil bath thermostated at a given temperature, which can be shifted up and down by hand, and the other the Infrared Image Furnace RHL-E25 (SINKU RIKO). The length change of a sample fiber was measured by a displacement meter and recorded on an $X-Y_{1}, Y_{2}$ recorder, together with the temperature of the silicone oil bath or of a thermocouple set near a sample in the Infrared Image Furnace. The good pen response (maximum pen speed, above $250 \mathrm{~mm} / \mathrm{sec}$ ) of the recorder to catch the shrinkage rate and the damped oscillation behavior of samples was confirmed by the measurement of deformation behaviors of the same samples by use of a Transient Time Converter. During the measurement of the length change, a about $1.7 \mathrm{~g}$ wt. for the infrared ray method or about $4.0 \mathrm{~g}$ wt. for the silicone oil method were loaded on a sample unless otherwise specified. The relative shrinkage $S$ was defined as $S=\left(L_{0}-L\right) / L_{0}$, where $L$ is the sample length and $L_{0}$ the initial sample length at room temperature.

\section{Results and Discussion}

Figure 1 shows the elapsed time dependence of the relative shrinkage $S$ for PVC fibers heated rapidly by immersing in silicone oil of given temperatures. Over $115^{\circ} \mathrm{C}$, after the initial abrupt shrinkage, damped oscillation behaviors of the deformation are observed, and then the sample length shows different behaviors; little by little decrease at 115 and $126^{\circ} \mathrm{C}$, good constancy against time at 137 and $151^{\circ} \mathrm{C}$, and slow increase at 169 and $181^{\circ} \mathrm{C}$. At 90 and $102^{\circ} \mathrm{C}$, the sample length does not oscillate but decreases gradually after the abrupt shrinkage upon rapid heating. Figure 2 shows the shrinkage of PVC fibers during three seconds after the rapid heating by immersing in silicone oil. At $118-183^{\circ} \mathrm{C}$, after the heating, the damped oscillation repeats four times. At 131 -

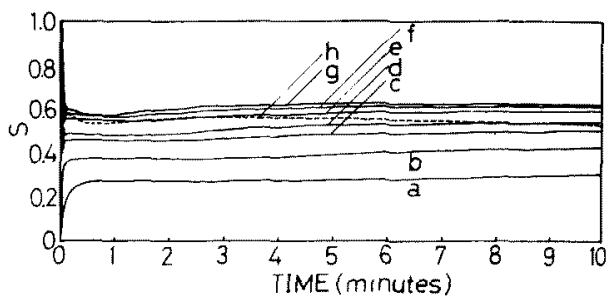

Fig. 1 Relative shrinkage $S$ vs. time curves during 10 minutes for PVC fibers $\left(L_{0}=25 \mathrm{~mm}\right.$ ) heated rapidly by immersing in silicone oil of given temperatures $\left(\mathrm{a}: 90^{\circ} \mathrm{C}, \mathrm{b}: 102^{\circ} \mathrm{C}\right.$, c: $115^{\circ} \mathrm{C}$, d: $126^{\circ} \mathrm{C}$, e: $137^{\circ} \mathrm{C}, \mathrm{f}: 151^{\circ} \mathrm{C}$ g: $169^{\circ} \mathrm{C}$ and $\mathrm{h}: 181^{\circ} \mathrm{C}$ )

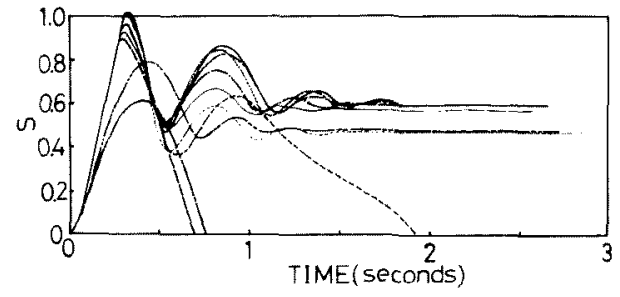

Fig. 2 Relative shrinkage $S$ vs. time curves for PVC fibers $\left(L_{0}=25 \mathrm{~mm}\right)$ during 3 seconds after the rapid heating by immersing in silicone oil of given temperatures $\left(-\cdots-118^{\circ} \mathrm{C},-\cdots: 131^{\circ} \mathrm{C}, \longrightarrow: 141^{\circ} \mathrm{C}\right.$, $-\cdots: 150^{\circ} \mathrm{C}, \cdots: 162^{\circ} \mathrm{C},-: 172^{\circ} \mathrm{C}$ - $; 183^{\circ} \mathrm{C},-\cdots--: 195^{\circ} \mathrm{C},--2: 207^{\circ} \mathrm{C}$, and -..- $217^{\circ} \mathrm{C}$ )

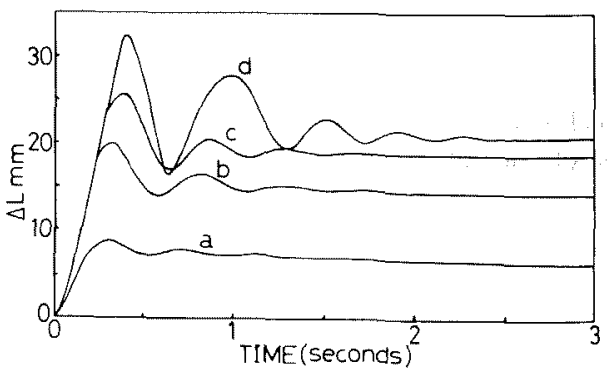

Fig. 3 The load dependence of the thermal deformation of PVC fibers heated rapidly by immersing in silicone oil at $145^{\circ} \mathrm{C}$ (a: $24.0 \mathrm{~g}, \mathrm{~b}: 14.0 \mathrm{~g}, \mathrm{c}: 8.7 \mathrm{~g}$ and $\mathrm{d}: 4.0 \mathrm{~g}$; $L_{0}=35 \mathrm{~mm}$ ) 
$183^{\circ} \mathrm{C}$, the sample contracts to the maximum relative shrinkage $S_{\max } \approx 1.0$ at the shrinkage rate $\left(d \Delta L\left(=L_{0}-L\right) / d t\right)$ of $105 \mathrm{~mm} / \mathrm{sec}$. However, the unusual high values of $S_{\max }$ shown in Figures 1 and 2 must be attributed, at least in some part, to the over-run of the upper grip of the sample holder under the high shrinkage rate and the inertia. At $118^{\circ} \mathrm{C}$, the shrinkage rate is a little less than those at $131-183^{\circ} \mathrm{C}$. Figure 3 shows the load dependence of the deformation of PVC fibers heated rapidly by immersing in silicone oil at $145^{\circ} \mathrm{C}$. With increasing the load on a sample, $S_{\max }$ decreases and the damped oscillation becomes meager. The shrinkage rate is $105 \mathrm{~mm} / \mathrm{sec}$ in the cases of $4.0,8.7$ and $14.0 \mathrm{~g}$ loads. With $24.0 \mathrm{~g}$ load, the rate is a little less than $105 \mathrm{~mm} / \mathrm{sec}$. Figure 4 shows the dependence on time of the relative shrinkage $S$ of PVC fibers heated by infrared ray. The shrinkage rate increases with increasing heating rate. The shrinkage rate at heating rates, 160.0 and $193.4 \mathrm{~K} / \mathrm{sec}$, are equally $102.4 \mathrm{~mm} / \mathrm{sec}$, which is almost equal to the shrinkage rate of $105 \mathrm{~mm} / \mathrm{sec}$ obtained for the heating by immersing in silicone oil at $131-183^{\circ} \mathrm{C}$. With increasing the heating rate, $S_{\max }$ is attained faster and the $S_{\max }$ value is increased. The time needed to attain $S_{\max }$ is 0.57 $\mathrm{sec}$ at $53.4 \mathrm{~K} / \mathrm{sec}$ and $0.32 \mathrm{sec}$ at 160.0 and 193.4 $\mathrm{K} / \mathrm{sec}$. The values of $S_{\max }$ at 160.0 and $193.4 \mathrm{~K} / \mathrm{sec}$ are about 0.83 . At $94.7-193.4 \mathrm{~K} / \mathrm{sec}$, two peaks appear in the time dependence curve of $S$. After the second shrinkage, the sample is elongated and then broken. At $20.0-53.4 \mathrm{~K} / \mathrm{sec}$, no peak appears in the $S$ vs. time curves, but a shoulder, which seems to be transformed gradually to a peak with increasing the heating rate, appears at about $0.6-$

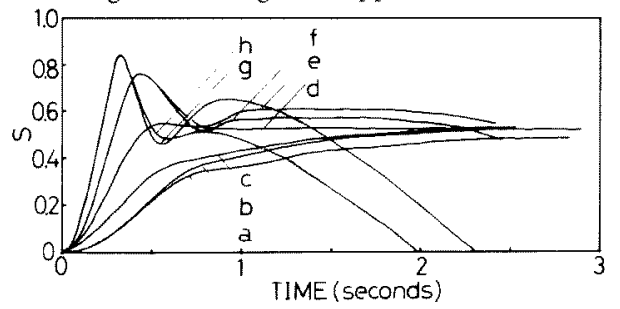

Fig. 4 Relative shrinkage $S$ vs. time curves for PVC fibers $\left(L_{0}=25 \mathrm{~mm}\right)$ during 3 seconds after the rapid heating by irradiating infrared ray at several heating rates

(a: $20.0 \mathrm{~K} / \mathrm{sec}, \mathrm{b}: 26.7 \mathrm{~K} / \mathrm{sec}, \mathrm{c}: 40.0 \mathrm{~K} / \mathrm{sec}$, d: $53.4 \mathrm{~K} / \mathrm{sec}$, e: $94.7 \mathrm{~K} / \mathrm{sec}$, f: 100.1 $\mathrm{K} / \mathrm{sec}, \mathrm{g}: 160.0 \mathrm{~K} / \mathrm{sec}$ and h: $193.4 \mathrm{~K} / \mathrm{sec}$ )
0.8 seconds after the rapid heating. Figures $5 \mathrm{a}-5 \mathrm{e}$ and 6 show the dependence of the deformation of PVC fibers on the initial sample length $L_{0}$. For the rapid heating by immersing in silicone oil at a temperature $130-210^{\circ} \mathrm{C}$ and infrared ray at heating rates $160.0,177.4$ and $181.6 \mathrm{~K} / \mathrm{sec}$, as seen in Figures 5 and 6 , the shrinkage rates are almost constant independent of $L_{0}$. These results suggest that in the rapid heating procedure the sample length decreases within a short time, probably by the necking. A similar result was

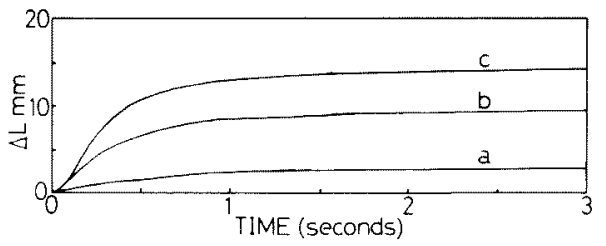

Fig. 5a The initial length dependence of the contraction length $\Delta L$ vs. time curves for PVC fibers heated rapidly by immersing in silicone oil at $102^{\circ} \mathrm{C}$ (a: $L_{0}=10 \mathrm{~mm}$, b: $L_{0}=25 \mathrm{~mm}$, and c: $L_{0}=35 \mathrm{~mm}$ )

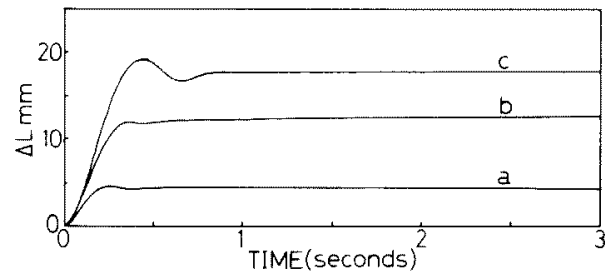

Fig. 5b The initial length dependence of the contraction length $\Delta L$ vs. time curves for PVC fibers heated rapidly by immersing in silicone oil at $119^{\circ} \mathrm{C}$ (a: $L_{0}=10 \mathrm{~mm}$, b: $L_{0}=25 \mathrm{~mm}$, and c: $L_{0}=35 \mathrm{~mm}$ )

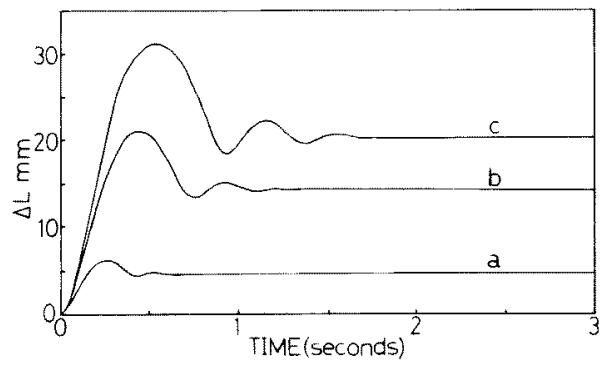

Fig. $5 c$ The initial length dependence of the contraction length $\Delta L$ vs. time curves for PVC fibers heated rapidly by immersing in silicone oil at $131^{\circ} \mathrm{C}$ (a: $L_{0}=10 \mathrm{~mm}$, b: $L_{0}=25 \mathrm{~mm}$, and c: $L_{0}=35 \mathrm{~mm}$ ) 


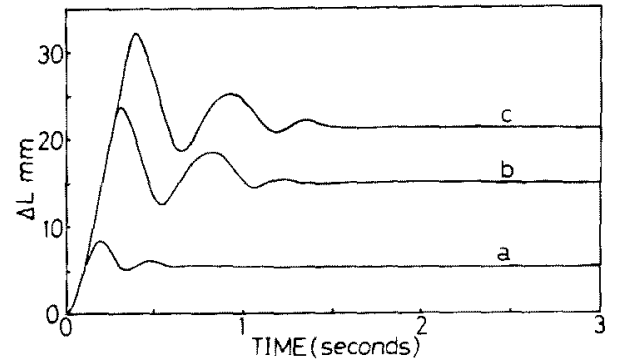

Fig. 5d The initial length dependence of the contraction length $\Delta L$ vs. time curves for PVC fibers heated rapidly by immersing in silicone oil at $144^{\circ} \mathrm{C}$ (a: $L_{0}=10 \mathrm{~mm}$, b: $L_{0}=25 \mathrm{~mm}$, and c: $L_{0}=35 \mathrm{~mm}$ )

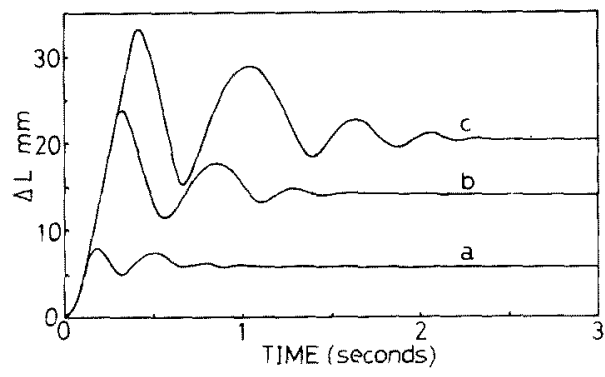

Fig. 5e The initial length dependence of the contraction length $\Delta L$ vs. time curves for PVC fibers heated rapidly by immersing in silicone oil at $155^{\circ} \mathrm{C}$ (a: $L_{0}=10 \mathrm{~mm}$, b: $L_{0}=25 \mathrm{~mm}$, and c: $L_{0}=35 \mathrm{~mm}$ )

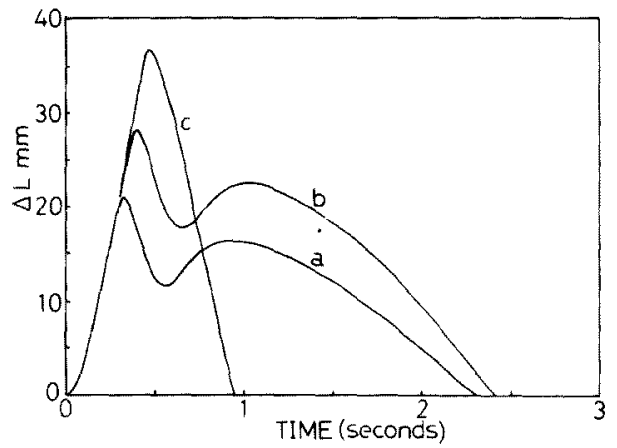

Fig. 6 The initial length dependence of the thermal deformation of PVC fibers heated rapidly by irradiating infrared ray (a: $160.0 \mathrm{~K} / \mathrm{sec}, L_{0}=25 \mathrm{~mm}$; b: 177.4 $\mathrm{K} / \mathrm{sec}, L_{0}=35 \mathrm{~mm}$; c: $181.6 \mathrm{~K} / \mathrm{sec}, L_{0}=$ $50 \mathrm{~mm}$ ) observed for PP fibers. The $L_{0}$ dependence of the shrinkage rate of PP fibers heated rapidly was investigated. The thermal deformation of PP fibers heated rapidly by irradiating infrared ray are shown in Figure 7. The shrinkage rate is $98.1 \mathrm{~mm} / \mathrm{sec}$ independent of $L_{0}$. Figure $8 \mathrm{a}$ shows the thermal deformation of PP fibers heated rapidly by immersing in silicone oil at $188^{\circ} \mathrm{C}$, which is higher than $T_{m}$ of PP. The shrinkage rate is $98.5 \mathrm{~mm} / \mathrm{sec}$ independent of $L_{0}$. At silicone oil temperature of $160^{\circ} \mathrm{C}$, below $T_{m}$, as seen in Figure $8 \mathrm{~b}$, the shrinkage rate changes dependently on $L_{0}$. The results shown in Figures 7 and $8 a$ suggest that the rapid heating procedure causes the necking of $P P$ fiber within a short period, resulting in the contraction of the sample. Figure 9 shows the thermal deformation of nylon- 6 fibers heated rapidly by immersing in silicone oil at given temperatures. The shrinkage rate and $S_{\max }$ increases with increasing the silicone oil temperature. At $163-192^{\circ} \mathrm{C}$, the shoulder appears at $0.3-0.6$ seconds after the rapid heating. This part seems to be transformed to a peak, with increasing the temperature of silicone oil. At $163-192^{\circ} \mathrm{C}, S_{\max }$ appears at about ten seconds after rapid heating. Figures $10 \mathrm{a}, \mathrm{b}$ and $\mathrm{c}$ show the $L_{0}$ dependence of the thermal deformation of nylon- 6 fibers heated rapidly by immersing in silicone oil at 214,227 and $245^{\circ} \mathrm{C}$. As seen in Figure 10 , the shrinkage rate varies with $L_{0}$. The value of $S_{\max }$ is almost constant irrespective of $L_{0}$. Figure 11 shows the

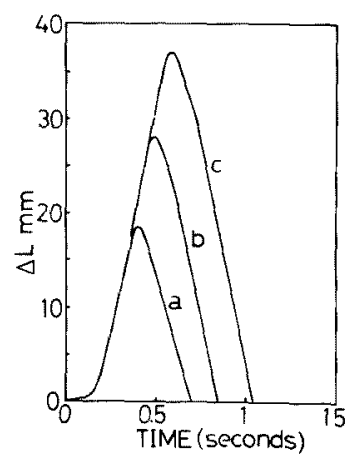

Fig. 7 The initial length dependence of the thermal deformation of the PP fibers heated rapidly by irradiating infrared ray $\left(L_{0}\right.$ and heating rate; a: $25 \mathrm{~mm}, 220.1 \mathrm{~K} / \mathrm{sec}, \mathrm{b}$ : $35 \mathrm{~mm}, 220.1 \mathrm{~K} / \mathrm{sec}, \quad \mathrm{c}$ : $50 \mathrm{~mm}, 181.4$ $\mathrm{K} / \mathrm{sec}$ ) 


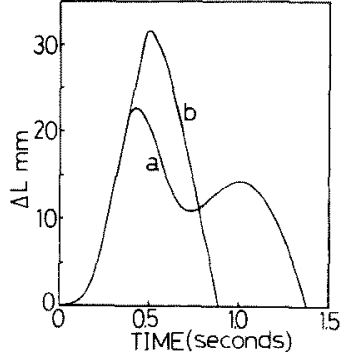

Fig. 8a The initial length dependence of the contraction length $\Delta L$ vs. time curves for PP fibers heated rapidly by immersing in silicone oil of $188^{\circ} \mathrm{C}$ (a: $L_{0}=25 \mathrm{~mm}$, b: $L_{0}=35 \mathrm{~mm}$ )

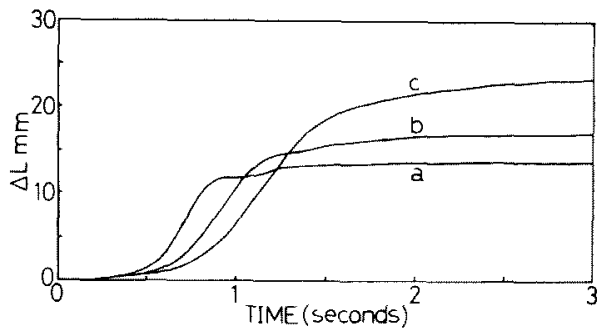

Fig. $8 \mathrm{~b}$ The initial length dependence of the contraction length $\Delta L$ vs. time curves for PP fibers heated rapidly by immersing in silicone oil of $160^{\circ} \mathrm{C}$ (a: $L_{0}=25 \mathrm{~mm}$, b: $L_{0}=35 \mathrm{~mm}$ and c: $L_{0}=50 \mathrm{~mm}$ )

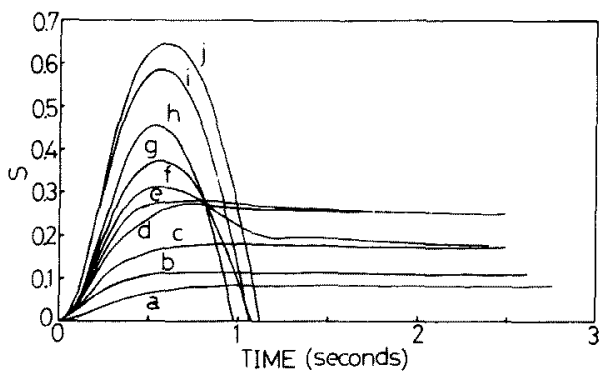

Fig. 9 Relative shrinkage $S$ vs. time curves for nylon-6 fibers $\left(L_{0}=50 \mathrm{~mm}\right)$ heated rapidly by immersing in silicone oil of given temperatures (a: $163^{\circ} \mathrm{C}$, b: $178^{\circ} \mathrm{C}$, c: $192^{\circ} \mathrm{C}$, d: $203^{\circ} \mathrm{C}$, e: $207^{\circ} \mathrm{C}$, f: $208^{\circ} \mathrm{C}$, g: $210^{\circ} \mathrm{C}$, h: $227^{\circ} \mathrm{C}$, it $233^{\circ} \mathrm{C}$ and j: $244^{\circ} \mathrm{C}$ )

$L_{0}$ dependence of the thermal deformation of nylon- 6 fibers heated rapidly by irradiating infrared ray at a heating rate of $199.4 \mathrm{~K} / \mathrm{sec}$. The shrinkage rate increases with increasing $L_{0}$, although the

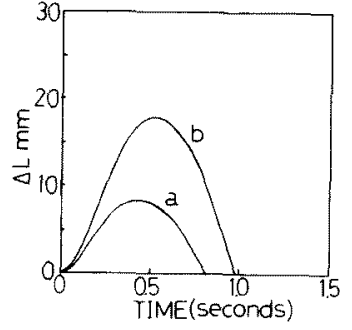

Fig. 10a The initial length dependence of the contraction length $\Delta L$ vs. time curves for nylon- 6 fibers heated rapidly by immersing in silicone oil at $214^{\circ} \mathrm{C}$ (a: $L_{0}=25 \mathrm{~mm}$ and b: $L_{0}=50 \mathrm{~mm}$ )

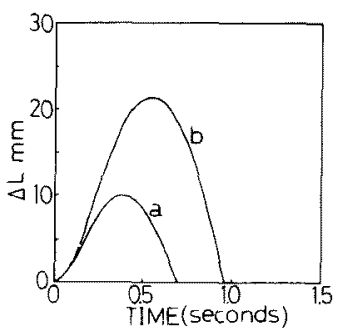

Fig. $10 \mathrm{~b}$ The initial length dependence of the contraction length $\Delta L$ vs. time curves for nylon- 6 fibers heated rapidly by immersing in silicone oil at $227^{\circ} \mathrm{C}$

(a: $L_{0}=25 \mathrm{~mm}$ and b: $L_{0}=50 \mathrm{~mm}$ )

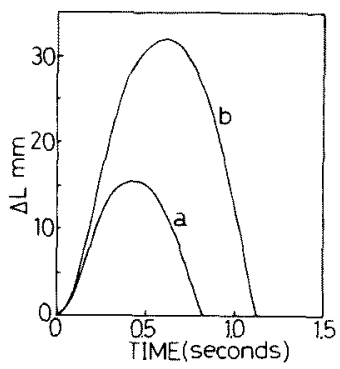

Fig. 10c The initial length dependence of the contraction length $\Delta L$ vs. time curves for nylon- 6 fibers heated rapidly by immersing in silicone oil of $244^{\circ} \mathrm{C}$

(a: $L_{0}=25 \mathrm{~mm}$ and b: $L_{0}=50 \mathrm{~mm}$ )

value of $S_{\max }$ is almost constant independent of $L_{\mathbf{0}}$. Figure 12 shows the load dependence of the thermal deformation of nylon- 6 fibers heated rapidly by irradiating infrared ray at a heating rate of $199.4 \mathrm{~K} / \mathrm{sec}$. The shrinkage rate, the value of $S_{\max }$ and the time to attain $S_{\max }$ depend on 


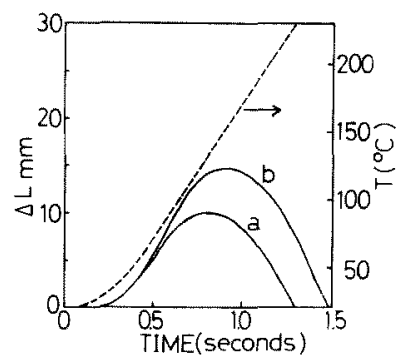

Fig. 11 The initial length dependence of the contraction length $\Delta L$ vs. time curves for nylon- 6 fibers heated rapidly by irradiating infrared ray at the heating rate of $199 \mathrm{~K} / \mathrm{sec}$ (a: $L_{0}=25 \mathrm{~mm}$ and b: $L_{0}=$ $35 \mathrm{~mm}$ )

--- : Temperature of a thermocouple set in the furnace.

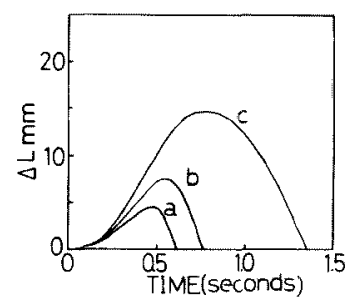

Fig. 12 The load dependence of the thermal deformation of nylon- 6 fibers heated rapidly by irradiating infrared ray at the heating rate of $199 \mathrm{~K} / \mathrm{sec}$ (a: $11.7 \mathrm{~g}$, b: $6.4 \mathrm{~g}$ and $\mathrm{c}: 1.7 \mathrm{~g} ; L_{0}=35 \mathrm{~mm}$ )

the load.

Prevorsek and Tobolsky reported ${ }^{3,4}$ the microscope observation that in the heating at a relatively slow heating rate the necking type shrinkage occurs at near $T_{m}$ for PP, polyethylene (PE) and nylon-66 fibers, but not for nylon- 6 fibers, indicating nylon-6 fiber contracts homogeneously. These facts suggest that a study on the melting phenomena of fibrous polymers must accompany a morphological examination. Iida and Sakami reported ${ }^{5}$ that in the drawing of an undrawn PP fiber the necking appears, but not for nylon- 6 fibers. In view of the results of Prevorsek and lida and their coworkers, it may be concluded that for PP and PVC fibers heated rapidly by irradiating infrared ray at a high heating rate and by immersing in silicone oil at temperatures, in the range $130-210^{\circ} \mathrm{C}$ for PVC fibers and over $T_{m}$ for PP fibers, the shrinkage of necking type occurs within a very short time duration. This doesn't happen for nylon-6 fibers under any rapid heating condition.

The damped oscillation behavior of thermal deformation observed distinctly for PVC fibers heated rapidly may be related to the damped inertial elasticity, which is expressed by the following equation ${ }^{6}$

$$
m \frac{d^{2} \gamma}{d t^{2}}+\eta \frac{d r}{d t}+G r=S
$$

where $m$ is the sample weight, $r$ the strain, $S$ the constant stress, $\eta$ the coefficient of viscosity and $G$ the Young's modulus.

This work was reported at the 8th Fiber Associated Meeting of The Society of Fiber Science and Technology, Japan, held in Tokyo in November, 1978.

\section{References}

1) B. Farrow and S.C. Simmens, J. Appl. Polymer Sci., 8, 2545 (1964)

2) N. Tanaka, Sen-i Gakkaishi, 33, T-363 (1977)

3) D. C. Prevorsek and A. V. Tovolsky, Textile Res. Jo, 33, 795 (1963)

4) D. C. Prevorsek, A. B. Coe and A. V. Tobolsky, ibid., 32, 960 (1962)

5) S. Iida and H. Sakami, Preprint of 19th Polymer Symposium, 885 (1970)

6) S. Iwayanagi, "Rheology", Asakura Shoten (1966) 